\title{
Performance improvement of aquaponics systems when using microbiological strains in them
}

\author{
Olga Krotova ${ }^{1, *}$, Sergey Chelbin $^{2}$, Maria Krotova $^{3}$, Olga Sangadzhieva ${ }^{4}$, and Kermen \\ Khalgaeva $^{4}$ \\ ${ }^{1}$ Don State Technical University, Gagarin Sq., 1, 344003 Rostov-on-Don, Russia \\ ${ }^{2}$ Branch of the Federal State Budgetary Institution "Russian Agricultural Center" in the Rostov \\ region, 344029 Rostov-on-Don, Russia \\ ${ }^{3}$ Volgograd State Agricultural University, 26 Universitetskiy ave, 400002 Volgograd, Russia \\ ${ }^{4}$ Kalmyk State University named after B.B. Gorogovikov, Pushkin St., 11, 358000 Elista, Russia
}

\begin{abstract}
The essence of the method of operation of the aquaponic system is to use the vital waste of aquatic animals as food for plants. At the first stage, the fish produces waste products. Then, in the second stage, microbes and worms convert the waste into fertilizersfor plants. During the process, at the third stage, plants consume the necessary products of excretion of living organisms. Aquaponics is an artificial ecosystem in which three types of living organisms are key: aquatic animals (usually fish or shrimp), plants and bacteria. This technology works on the principle of an ecosystem of fish and plants: fish provides foodto plants, and plants purify water and are environmentally friendly. The essence of this method is to use the vital waste of aquatic animals (fish, shrimp) as a nutrient medium for plants. These are chemicals such as nitrogenous, potassium, phosphorus compounds, carbon dioxide. Thanks to aquaponic farms, the costs of water and other natural resources, soil pollution and the use of insecticides are already being reduced in different places of our planet. Such systems are a sustainable ecosystem capable of producing organic matter that does not contain toxic substances often present in vegetables grown by traditional methods.
\end{abstract}

\section{Introduction}

The progress of the food industry is connected with the progress of science. Competition in the food market and the deterioration of the environmental situation are one of the important factors of development. All this leads to the creation and improvement of agricultural practices.

Currently, there are global environmental problems, including food production, which directly concern agriculture. This is the impoverishment and destruction of arable land, the absence and pollution of fresh water. In addition, scientific progress does not always bring benefits. Putting high yields in the first place in a short time, manufacturers use fertilizers

\footnotetext{
*Corresponding author: Alb9652@yandex.ru
} 
that negatively affect the health of consumers in the future. Therefore, new approaches to agriculture are already needed to obtain high-quality products without harming the surrounding world and the consumer.

The purpose of the research work is to study a high - tech method of farmingaquaponic. The relevance and importance of the chosen topic lies in the fact that aquaponics today is the most promising direction in terms of production technologies and scientific research. This system can be used all year round, regardless of climatic and soil conditions. aquaponics allows you to look at agriculture through the prism of the latest technologies in agriculture. This technology will take a very important place in the development of agriculture in the future, since the production process excludes the use of chemical fertilizers. The process of chemicalization and purification occurs naturally in a closed cycle. Aquaponics is considered the most environmentally friendly way of growing plants due to the lack of chemical fertilizers [1-3]. The practical significance of this method is quite large. For example, the development of this technology of growing plants can significantly reduce the cost of obtaining fresh vegetables in closed conditions in the offseason, which will have a positive impact on the health of consumers.

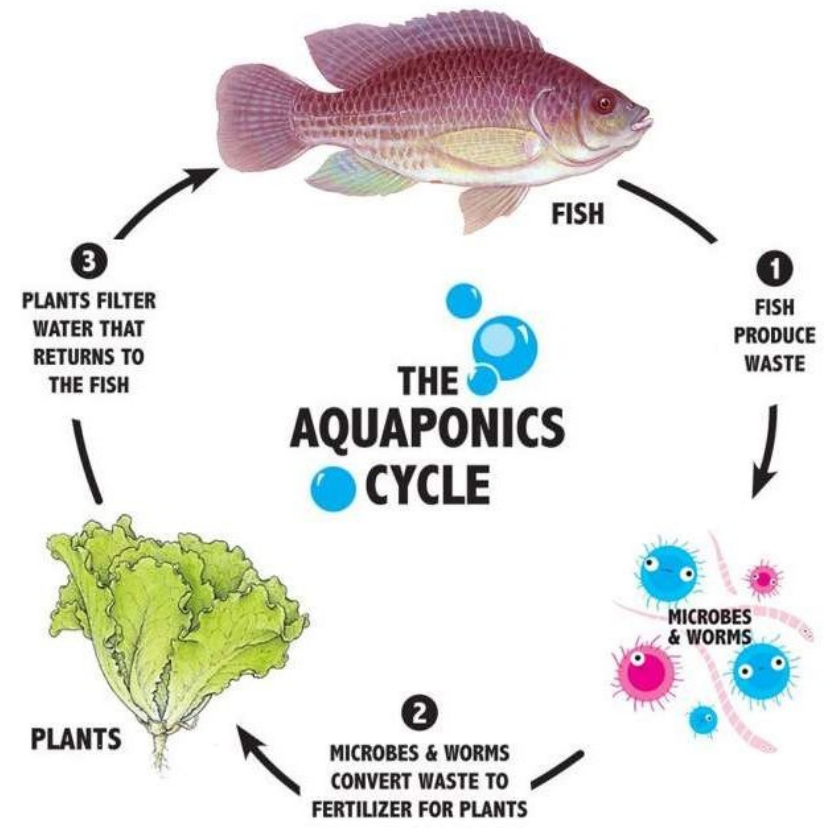

Fig. 1. Aquaponics cycle

The essence of the method of operation of the aquaponic system is to use the vital waste of aquatic animals as food for plants. At the first stage, the fish produces waste products. Then, in the second stage, microbes and worms convert the waste into fertilizers for plants. During the process, at the third stage, plants consume the necessary productsof excretion of living organisms. These are chemicals such as nitrogenous, potassium, phosphorus compounds, carbon dioxide.

Aquaponics is an artificial ecosystem in which three types of living organisms are key: aquatic animals (usually fish or shrimp), plants and bacteria. This technology works on the principle of an ecosystem of fish and plants: fish provides food to plants, and plants purify water and are environmentally friendly. The essence of this method is to use the vital waste of aquatic animals (fish, shrimp) as a nutrient medium for plants [4-6]. 
Wastewater generated as a result of malnutrition of feed or the vital activity of fish accumulates in the water due to closed circulation in most aquaculture systems. Water containing effluents becomes toxic and dangerous to animals in high concentrations, but at the same time contains nutrients that are necessary for plant nutrition and growth. Aquatic animals emit toxic waste products for themselves: chemical compounds.

The accumulation of these substances in the water is a serious problem, both in closed industrial aquaculture and in a conventional aquarium. These substances are absolutely necessary in hydroponics and are added to water to obtain nutrient solutions for plants. In aquaponics, this problem is solved in this way: the vital products of fish are removed by bacteria and plant [7-9].

Although aquaponics mainly consists of these two parts, aquaponic systems are usually grouped into several components or subsystems responsible for effective waste disposal, adding a base for acid neutralization or enriching water with oxygen.

The main product of microbiological decomposition of fish waste and other representatives of aquatic fauna is ammonia-NH3, released and dissolved in water, which, in turn, during the vital activity of aerobic bacteria, as well as oxygen dissolved in water $\mathrm{O} 2$, oxidizes ammonia and its gas derivatives - amine, forming nitrites and nitrates "saltpeter". This reduces the chemical toxicity of water in the vital activity of animals and allows plants to remove the resulting nitrate compounds, consuming the necessary elements for their life support.

Plants can also absorb ammonia directly from water, but dissolved salts are absorbed much more readily and more easily. Colonies of bacteria living in the soil and the root system of plants in a closed cycle of aquaculture purify water from toxic substances, and plants consume salts, gases and chemical elements dissolved in water - nitrates, nitrogen $\mathrm{N}$, phosphorus $-\mathrm{P}$, carbon dioxide - $\mathrm{CO} 2$ and, to a certain extent, enrich oxygen into water, which is also returned to animals in the form of soda.

Thus, this system simulates the natural circulation of substances in nature, where cultivated plants act as producers, aquatic animals, as consumers - consults, and bacteria as reducers [9-11].

Typical elements of an aquaponics system include: a fish breeding tank; a sump: an aggregate powered to absorb feed residues, lost biofilm and to separate small particles; a biofilter: a place where nitrifying bacteria grow and turn ammonia into nitrates necessary for plant nutrition; hydroponics subsystems: a part of the system in which plants are grown through the absorption of excess nutrients from water; a tray: the lowest point in the system in which water enters and rises back into tanks.

Aquaponics is studied all over the world. Figure 2 shows an aquaponics system developed by students in the Nature Laboratory of the Rhode Island School of Design in the United States of America. 


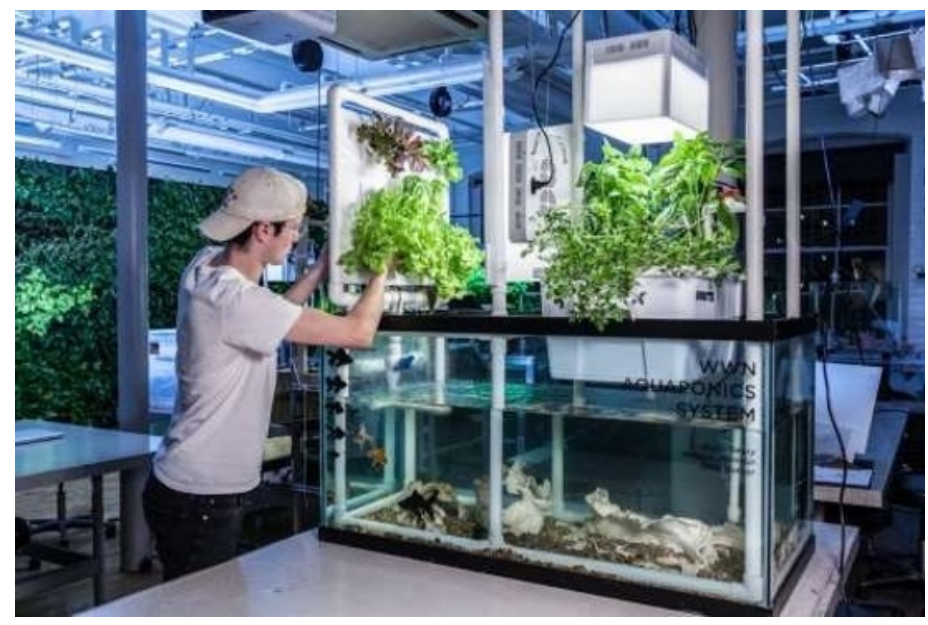

Fig. 2. Aquaponics system developed by students in the Nature Laboratory of the Rhode Island School of Design

The aquaponics system developed in the Nature Laboratory of the Rhode Island School of Design was built using a one hundred and thirty gallon aquarium, PVC pipelines, two LED lamps for growing, two separate beds for growing, various pumps and filters. This project illustrates why aquaponics is an important event in the future of food production. This system is installed in the student canteen as a reminder of the importance of fresh and nutritious food in the human diet [12].

Depending on the cost and complexity of the aquaponic system, waste tanks, biofilters or subsystems of hydroponics can be combined into one component or subsystem, which does not allow the flow from the aquaculture part of the system to the part of the hydroponics system. Aquaponics makes it possible to significantly reduce, but in some cases even reduce to zero, the discharge of wastewater.

In the valve system, it is desirable to grow green-leaved plants, such as beans, peas, cauliflower, radishes, tomatoes, melon, strawberries, pumpkin, onion, pepper. In these plants, at the early stages of development, there is a need for nitrogen, which is just released into the water as a result of the vital processes of fish. Within this system, the number of aquatic animals directly depends on the number of cultivated plants $[13,14]$.

In Russia, the first aquaponic farm is being built in the Krasnodar Territory in the village of Maryina Roscha (near Gelendzhik). Here, using the unique aquaponics technology, tilapia fish and green crops, including lettuce and mint, will be grown. At the moment, the construction is at the initial stage [15-16].

The area of the farm is 1.3 hectares, two modules will be located here, the design capacity of each is 40 tons of fish per year. Aquaponics is a very organic method of growing plants and fish in a closed cycle. Fish saturates water with

nutrients necessary for optimal plant growth. In the future, it is possible to grow such fish species as trout, baramundi and sturgeon. Aquaponics is an interconnected hybrid system of pond agriculture and hydroponics. The system for growing vegetables and herbs can be both large and small, depending on the wishes, and is potentially able to provide fish and vegetables in huge quantities [17].

Changing the concept requires not only opportunities in agriculture - at least in the development of small farms, but also in the way of harvesting and its further consumption.

The application of aquaponics on an industrial scale is shown in Figure 3. 


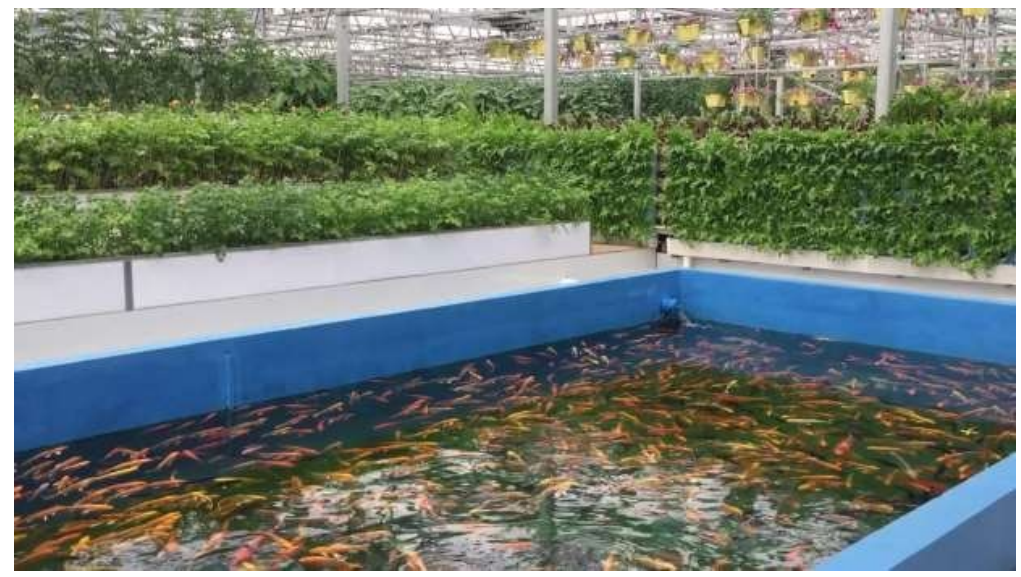

Fig. 3. Application of aquaponics on an industrial scale

In the first section, the relevance of scientific research in the field of aquaponics was considered. The environmental friendliness of this method is considered.

Fish are kept in a tank with filtered water from all harmful impurities. No human waste gets into the water, for example, garbage, polyethylene, petroleum products. In addition, the absence of mud in the water excludes the appearance of a grassy smell in the fish. Fish production takes place without the use of synthetic mineral fertilizers that regulate growth, artificial food additives, as well as without genetically modified products

Thanks to aquaponic farms, the costs of water and other natural resources, soil pollution and the use of insecticides are already being reduced in different places of our planet. Such systems are a sustainable ecosystem capable of producing organic matter that does not contain toxic substances often present in vegetables grown by traditional methods.

\section{Materials and methods}

Criteria for evaluating the effectiveness of the studied object: the experiment was carried out in two versions: with the addition of a bacterial strain (experiment) and without the introduction of a bacterial strain (control).

For statistical data processing, we used the Microsoft Office Excel program. Statistical processing of the results of the study was carried out using the Student's criterion. The changes at $\mathrm{p} \leq 0.95$ were considered to be significantly significant.

Parameters controlled in the studies: Table 1 shows data on the cultivation of tilapia in an aquaponic installation for 30 days in the experiment.

Table 1. Dynamics of mass characteristics of tilapia in an aquaponic installation

\begin{tabular}{|l|l|l|}
\hline Indicator & Initial state & After 30 days \\
\hline Weight, $\mathrm{g}$ & $246,35 \pm 11,07$ & $389,81 \pm 11,73$ \\
\hline Absolute increase, $\mathrm{g}$ & - & 143,46 \\
\hline Average daily increase, g/day & - & 4,74 \\
\hline Average daily growth rate, $\%$ & - & 1,52 \\
\hline Mass accumulation coefficient, units. & - & 0,10 \\
\hline Fulton fatness coefficient, units. & $0,56 \pm 0,02$ & $0,68 \pm 0,01$ \\
\hline
\end{tabular}

At the end of the experiment, a study of the physiological parameters of tilapia in both versions of the experiment was conducted, presented in Table 2. 
Table 2.Dynamics of physiological and biochemical parameters of tilapia blood when grown in an aquaponic installation

\begin{tabular}{|l|l|l|}
\hline Indicator & Experience & Control \\
\hline ESR, $\mathrm{mm} / \mathrm{h}$ & $3,83 \pm 0,14$ & $3,82 \pm 0,15$ \\
\hline Hemoglobin, g / & $141,92 \pm 4,271$ & $43,51 \pm 1,210$ \\
\hline Total protein, g/l & $45,30 \pm 0,86$ & $46,70 \pm 0,34$ \\
\hline
\end{tabular}

The values of hemoglobin, ESR, and total protein were stable in both versions of the experiment, and did not changesignificantly. In the control, compared with the experiment, the hemoglobin index of tilapia was higher by $3.7 \%$.

Thus, it can be concluded that the culture fluid Serratia ficaria TP3 does not significantly affect the blood parametersof tilapia.

Strawberries were treated with the same solution of the bacterial strain. Previously, before planting the plants in the system, the tubers were soaked in a solution of a bacterial strain. Then, during the entire experiment, the plants were treated in the experiment by spraying every 10 days. The length of the stem at the end of the experiment in the experiment is $69 \mathrm{~mm}$, and in the control $46.2 \mathrm{~mm}$. Figure 4 shows the change in the length of the stem.

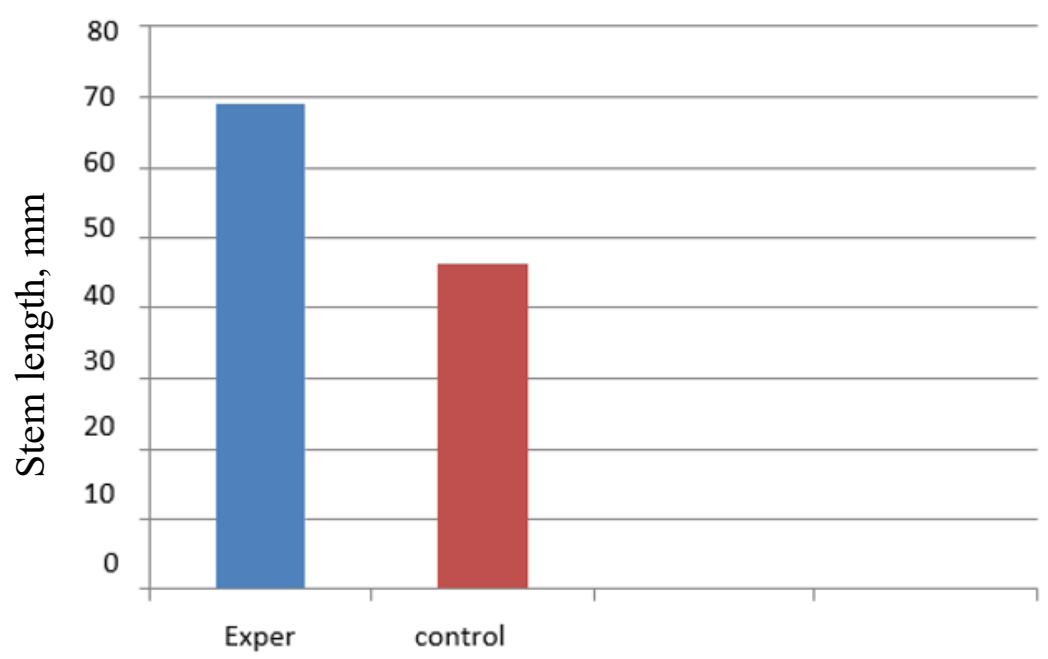

Fig. 4. The length of the strawberry stem

When harvesting, the level of nitrates in strawberries was much lower in the experiment than in the control, which proves the effectiveness of the biological product.

Figure 5 shows the level of nitrates in strawberries. 


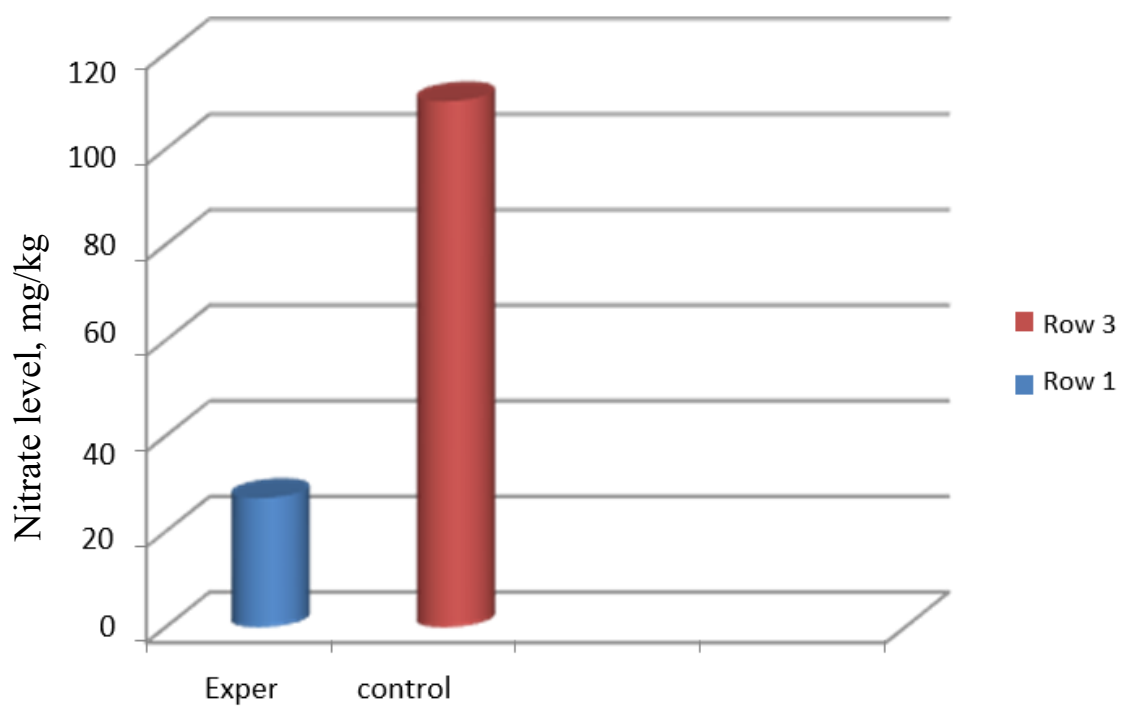

Fig. 5. The level of nitrates in strawberries

Therefore, the treatment of strawberries with a solution of a bacterial strain by spraying plants at the stage of creating the first brush has the greatest positive effect on the growth indicators of strawberries in the flowering phaseand in the fruiting phase. The accumulation of strawberry nitrates was significantly below the level of the maximum

permissible concentration.

Equipment, experimental installations, instruments, equipment, accessories:

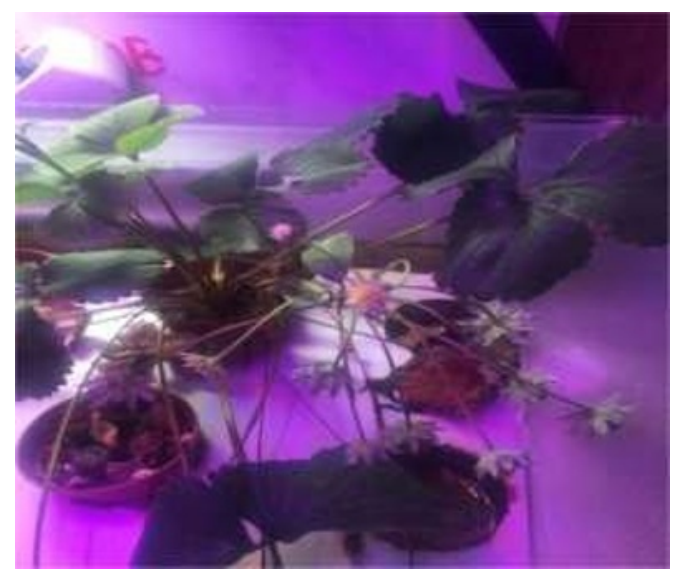

Fig. 6. Shows an aquaponic plant for growing strawberries.

Conditions and procedure for conducting experiments, the composition of experiments.

Tilapia was grown in modular systems with a volume of 500 liters, with a water temperature of $28 \pm 1{ }^{\circ} \mathrm{C}$, an oxygen content of $5 \pm 1 \mathrm{mg} / \mathrm{l}$, a pH of $7 \pm 1$, nitrites-0.1-0.2 $\mathrm{mg} / \mathrm{l}$, ammonia-ammonium-0.5-1 mg/l. The density of planting tilapia in growing pools was 35 copies. per $1 \mathrm{~m} 3$ in experience and control. Together with tilapia, the method of aquaponics was used to grow strawberries of the "Mashenka" variety. The experiment was carried out in two versions: with the addition of a bacterial strain (experiment) and without the introduction of a bacterial strain (control). 
In the experiment, a microbiological biological product based on a strain of bacteria was used to accelerate plant growth and reduce the proportion of nitrates in the production. The culture liquid of the isolate has been previously tested and is a solution that is safe for fish and the environment. To prepare a suspension of the Serratia ficaria SP3 isolate, it was cultivated on potato agar with continuous stirring on a rocking machine $(120 \mathrm{rpm})$ at a temperature of 280

${ }^{\circ} \mathrm{C}[7,8]$.

A sterile scalpel was scraped from the surface of the fish body, the resulting material was placed on solid nutrientmedia and rubbed with a spatula. At the same time or at the end of the crops, smears were made from the mucus of the body surface, gill sections, as well as smears-prints from internal organs, staining them with Leffler's methylene blue, by Gram.

\section{Results and Discussion}

Processing of research results and their analysis. Studies have been conducted to study the microflora of the tilapia surface during the joint cultivation of tilapia and various agricultural plants in an aquaponic installation. The number of cells from the tilapia surface in a pure sample was $4.2 \cdot 107 \mathrm{CFU} / \mathrm{ml}$. In the sample without the addition of a bacterial strain, the development of a similar microflora was observed, but less intense. The number of cells was $5.3 \cdot 107 \mathrm{CFU} / \mathrm{ml}$. The working solution of the isolate Serratia ficaria TP3 activated the physiological processes of the strawberry variety "Mashenka", had a favorable effect on the development of plants, contributed to a decrease in the level of nitrates and an increase in yield: the yield of strawberries in the experiment with the culture liquid Serratia ficaria TP3 was $5.2 \mathrm{~kg} / \mathrm{m} 3$, and in the control $-3.8 \mathrm{~kg} / \mathrm{m} 3$. The effect of the culture fluid Serratia ficaria TP3 on tilapia was not observed. Aquaponics is a progressive direction of agricultural development. It has many advantages, both for the consumer and for the manufacturer. But the most important thing is that aquaponics solves the problems of the impact of traditional agriculture on the environment. Aquaponics is widely used in the world, but the distribution of its use is uneven. Aquaponics has become stronger in the countries of Asia, Europe and North America. In Russia, the method of joint cultivation of fish and plants is not so popular yet, but it is already used by some companies.

This method of farming is based on the interaction of several groups of living organisms that mutually affect each other, as in natural ecosystems. It is the use of the closed system principle that makes aquaponics a unique, efficient and environmentally friendly type of agriculture. The main processes in aquaponic systems are nitrification, phosphorylation, photosynthesis and root nutrition of plants, the processes of nutrition and excretion in fish. All theseprocesses are absolutely natural and occur in nature.

Aquaponics has several methods of management, so you can choose the best conditions for growing plants and fish.

\section{Conclusions}

Many plant crops can be grown in aquaponics. Leaf lettuce, strawberries, onions of various varieties, spicy herbs, tomatoes, cucumbers, peppers have become widespread.

Studies were conducted to study the microflora of the tilapia surface during the joint cultivation of tilapia and various agricultural plants in an aquaponic installation.

Aquaponics in Russia is a promising direction. This is an eco-friendly and compact type of production that can exist within the city. High productivity allows us to provide environmentally friendly products to the consumer in a fairly short time with proper organization of production. 
The transition of agriculture from soil and groundwater pollution to "clean" aquaponic production is a big step towards an environmentally friendly future.

\section{References}

1. Z. Schmautz, C.A. Espinal, A.M. Bohny, F. Rezzonico, R. Junge, E. Frossard, T.H.M., BMC Microbiology, 21(1), 12 (2021)

2. G.L. Lenz, A.Loss, C.R. Lourenzi, D. Luiz de Alcantara Lopes, Aquaculture Research, 52(10), pp. 5008-5021(2021)

3. A.A. Bracino, J.L. Espanola, A.A. Bandala, E.P. Dadios, E. Sybingco, R.R.P. Vicerra, Journal of Advanced Computational Intelligence and Intelligent Informatics, 25(5), 632-638 (2021)

4. R.S.Concepcion, S.C. Ii, Lauguico, J.D. Alejandrino, A.A. Bandala, E. Sybingco, R.R.P. Vicerra, E.P. Dadios, J.L., Journal of Advanced Computational Intelligence and Intelligent Informatics, 25(5), 610-617 (2021)

5. M. Eck, I. Szekely, S. Massart, M.H. Jijakl, Acta Horticulturae, 1321, 213-219 (2021)

6. P.Derikvand, B. Sauter, L.Y. Stein, Applied Microbiology and Biotechnology, 105(18), 7009-7021(2021)

7. W.A. Lennard, Aquaculture and Fisheries, 6(5), 495-505 (2021)

8. John, J., Mahalingam P., M.P.R., Automated Fish Feed Detection in IoT Based Aquaponics System, 8th International Conference on Smart Computing and Communications: Artificial Intelligence, AI Driven Applications for a Smart World, ICSCC 2021, 286-290 (2021)

9. Z.J. Ong, A.K. Ng, T.Y. Kyaw, Intelligent Outdoor Aquaponics with Automated Grow Lights and Internet of Things, Proceedings of 2019 IEEE International Conference on Mechatronics and Auto mation, ICMA 2019, 8816577, 1778-1783 (2019)

10. D. Karimanzira, T. Rauschenbach, Information Processing in Agriculture, 6(3), 375385 (2019)

11. O. Witzel, S. Wilm, D. Karimanzira, Baganz, Information Processing in Agriculture, 6(3), 326-334(2019)

12. V. Orobets, E. Lisovets, S. Zabashta, A. Ermakov, Control of fish parasites in aquaculture, IOP Conference Series: Earth and Environmental Science. 12th International Scientific Conference on Agricultural Machinery Industry, INTERAGROMASH 2019, 012065 (2019)

13. A.L.J. Rico, International Journal of Recent Technology and Engineering, 8(3), 76507653 (2019)

14. G. G. Matishov, E. N. Ponomareva, State and prospects of development of aquaculture biotechnologies in the south of Russia, Collection of joint publications of the staff of the UNC RAS and DSTU. Under the general editorship of G. G. Matishov, B. Ch. Meskhi, I. V. Karmanov (ed.). Rostov-on-Don, 18-20 (2020)

15. M.F. Mohd Pu'Ad, K.A. Sidek, M. Mel, International Journal of Innovative Technology and Exploring Engineering, 9(1), 4181-4184(2019)

16. H.H. Bennouri, A.A. Berqia, N.K. Patrick, Journal of Communications, 14(12), 11911197 (2019)

17. K. Al-Kodmany, Modeling and Optimization in Science and Technologies, 17, 203232 (2020) 